\title{
Series preface
}

Twenty years after the EU introduced the concept of 'European Citizenship' in the Treaty of Maastricht, the European Commission proclaimed 2013 the 'Year of European Citizenship'. This was done to draw additional attention to a perceived problem: why don't Europeans realize their rights as European citizens? The term 'realize' was used here to mean both being aware of these rights and demanding, using and thereby materializing them. In this year, the European Commission also awarded a consortium of 26 institutes from 19 countries in and outside Europe, coordinated by Utrecht University, a major research grant to carry out a four-year research project to study this problem. This multinational and multidisciplinary project, entitled bEUcitizen, sets out to identify and analyse which impediments hinder European citizens from realizing these rights and why.

Now, almost four years later, the topic of EU citizenship is even more pertinent, considering the increasing challenges for the EU, such as the economic and financial crisis, widening inequality, the rise of populism, widespread contestation of the European integration process, the rule of law crisis in several Member States and Euro-scepticism, challenges to open borders and mobility and the Brexit referendum.

Whereas the situation wherein the EU has arrived is serious, it may not necessarily be desperate. The 'end of the growth of European integration' may, paraphrasing the words of T.S. Eliot, also be the beginning, that is, the beginning of new forms of integration, as, for instance, set out in the Commission's White Paper on the Future of Europe, or the beginning of the development of a more mature concept of citizenship, or of alternative forms of EU citizenship.

These developments make a book series on European citizenship more than relevant. The bEUcitizen book series builds upon the results of the research carried out within the bEUcitizen consortium. The series looks into the main issues relating to EU citizenship and citizenship in general from different angles and from a multidisciplinary perspective. The book series approaches and analyses the concept of EU citizenship in a coherent and integrative manner, yet from a set of unique and distinct perspectives: 
(a) Inter- and multidisciplinary: Our point of departure is that citizenship is not merely a legal notion of rights produced by statute and/ or case law, but that it has developed and develops in the interchange between rules and practices, between law, politics and society. Hence studying citizenship issues requires an interdisciplinary approach. In our project we have therefore assembled an interdisciplinary team of authors and contributors from various relevant disciplines who have contributed to the book series: law, philosophy, history, sociology, political science, economics and policy studies.

(b) The book series addresses both the normative and empirical dimensions of citizenship.

(c) We can learn from other times and places and from the comparison between these. Therefore we added a historical and comparative dimension to the analysis.

(d) As to the latter: The contributors come from a variety of national/ cultural backgrounds within the EU: 17 Member States plus Turkey (with a diaspora in Europe) and Israel (with a diaspora from Europe). That means that the project is rooted in many different countries, also potentially providing interest and readership in many countries both within and outside the EU.

Thus the book series should help to further stir the debate on citizenship questions in Europe and beyond. Without the help and support of several people this book and the book series on Interdisciplinary Perspectives on European Citizenship would not have become a reality. The bEUcitizen project was generously supported by the European Commission under the European Union's Seventh Framework Programme for research, technological development and demonstration under grant agreement no. 320294, for which we would like to express our gratitude. We are also very grateful to all those who contributed to this book and the bEUcitizen research, without whose enduring commitment the project could not have been concluded successfully. As ever, Edward Elgar Publishing has offered an exemplary service.

Sybe de Vries (coordinator of the bEUcitizen project) Utrecht, the Netherlands 31 August 2017 